\title{
A new approach to collaborative creativity support of new product designers
}

Citation for published version (APA):

Bitter-Rijpkema, M., Sloep, P., Sie, R., Van Rosmalen, P., Retalis, S., \& Katsamani, M. (2011). A new approach to collaborative creativity support of new product designers. International Journal of Web Based Communities, 7(4), 478-492. https://doi.org/10.1504/IJWBC.2011.042992

\section{DOI:}

10.1504/IJWBC.2011.042992

Document status and date:

Published: 01/01/2011

Document Version:

Peer reviewed version

\section{Document license:}

CC BY-NC-ND

Please check the document version of this publication:

- A submitted manuscript is the version of the article upon submission and before peer-review. There can be important differences between the submitted version and the official published version of record. People interested in the research are advised to contact the author for the final version of the publication, or visit the DOI to the publisher's website.

- The final author version and the galley proof are versions of the publication after peer review.

- The final published version features the final layout of the paper including the volume, issue and page numbers.

Link to publication

\section{General rights}

Copyright and moral rights for the publications made accessible in the public portal are retained by the authors and/or other copyright owners and it is a condition of accessing publications that users recognise and abide by the legal requirements associated with these rights.

- Users may download and print one copy of any publication from the public portal for the purpose of private study or research.

- You may not further distribute the material or use it for any profit-making activity or commercial gain

- You may freely distribute the URL identifying the publication in the public portal.

If the publication is distributed under the terms of Article 25fa of the Dutch Copyright Act, indicated by the "Taverne" license above, please follow below link for the End User Agreement:

https://www.ou.nl/taverne-agreement

Take down policy

If you believe that this document breaches copyright please contact us at:

pure-support@ou.nl

providing details and we will investigate your claim.

Downloaded from https://research.ou.nl/ on date: 26 Apr. 2023 


\title{
A new approach to collaborative creativity support of new product designers
}

\section{Marlies Bitter-Rijpkema*, Peter B. Sloep, Rory Sie and Peter van Rosmalen}

Centre for Learning Sciences and Technologies,

Open Universiteit,

Valkenburgerweg 177, $64 \backslash 9$ AT Heerlen, The Netherlands

Fax: +3-45-5762800

E-mail: marlies.bitter@ou.nl

E-mail: peter.sloep@ou.nl

E-mail: rory.sie@ou.nl

E-mail: peter.vanrosmalen@ou.nl

*Corresponding author

\section{Symeon Retalis and Mary Katsamani}

Department of Digital Systems, University of Piraeus,

150 Androutsou Odyssea, 185, 32 Piraeus, Greece

Fax: +30-210-414-2767

E-mail: retal@unipi.gr

E-mail: marykatsamani@gmail.com

\begin{abstract}
Effective collaborative creativity is crucial to contemporary professionals who have to continuously produce innovative products and services. The technological nature and complexity of the innovations require team work, among specialists from different disciplines. Often these teams work in a distributed fashion, across boundaries of time and place. Therefore, they need electronic 'spaces' that support ('afford') their creative collaboration. Co-creativity support is not only a matter of making appropriate groupware spaces available but also of providing concurrent support in all these dimensions. These considerations inspired the development of the idSpace platform. idSpace is a collaboration platform integrating a variety of creativity tools with pedagogy-based guidance. It aims to optimise both the use of creativity techniques themselves and of the supporting processes of team collaboration and knowledge creation. In this paper, we zoom in on knowledge-sharing strategies for collaborative creativity (KS4CC). We show how collaborative creativity can be enhanced via integration of pattern-based pedagogical flow support, including suggestions of optimal use of creativity techniques. The KS4CC strategies consist of a merger of learning and collaboration flow patterns with support for the application of creative techniques.
\end{abstract}

Keywords: work-based learning; collaboration; creativity; innovation; adaptable recommendations; spaces for co-creativity; pedagogical flow patterns. 
Reference to this paper should be made as follows: Bitter-Rijpkema, M., Sloep, P.B., Sie, R., van Rosmalen, P., Retalis, S. and Katsamani, M. (2011) 'A new approach to collaborative creativity support of new product designers', Int. J. Web Based Communities, Vol. 7, No. 4, pp.478-492.

Biographical notes: Marlies Bitter-Rijpkema works as an Assistant Professor at CELSTEC at the Open University of the Netherlands. Her research focuses on creative problem solving and knowledge building in virtual communities. Over the years, she worked in various roles in (inter)national (EU) projects and operated as liaison officer for the Dutch Digital University Consortium. As an Educational Technologist, she participated in the design of the virtual company learning project, multimedia business simulations, peer assessment and IT-based learner support thesis writing and collaborative learning. Her actual research interests focuses on knowledge support for collaborative creativity, inventive problem solving in distributed teams, self-organised learning in innovation communities and business modelling for open education and innovation. She currently directs pedagogical design teams developing learning and innovation networks for librarians.

Peter B. Sloep is a Professor of Technology Enhanced Leaning at the Centre for Learning Sciences and Technologies of the Open University oft he Netherlands. He directs its Research and Technology Development Programme on Learning Networks, online social networks that have been designed with non-formal education in mind. His research focuses on learning and professional development as well as innovation enhancement in networked, online environments. His particular interest includes the social affordances and their technical implementation in services that make learning in such environments effective, efficient, enjoyable and sustainable. He is a reviewer of several journals on technology enhanced learning. He also chairs the Dutch standards body's (NEN) committee on learning technologies.

Rory Sie is a PhD student at the Centre for Learning Sciences and Technologies (CELSTEC) at the Open University of the Netherlands. His research focuses on the application of game theory and artificial intelligence techniques to creativity, (networked) innovation and (organisational) learning.

Peter van Rosmalen has been active in educational technology since the early $80 \mathrm{~s}$ both as a Consultant for the financial sector and for large industrial companies both in Denmark and the Netherlands and in a variety of European research projects around authoring tools, simulations, computer supported cooperative learning, knowledge management, the application of language technologies, creativity and most recently serious games. In 2000, he was co-Founder and Director of Aurus KTS, a company in e-learning and knowledge management. Since 2003, he is a Researcher at CELSTEC, Open University of the Netherlands. His current research focuses research on the application of language technologies, learner support services and serious games.

Symeon Retalis is an Associate Professor at the Department of Digital Systems, University of Piraeus in Greece. He holds a Diploma of Electrical and Computer Engineer and a PhD in this field, and an MSc in Information Technology-Knowledge-Based Systems. His research interests lie in the development of web-based learning systems, design of adaptive hypermedia systems, web engineering, and human computer interaction. He currently is the Director of the Computer Supported Learning Engineering Laboratory (CoSy LLab). He has coordinated and participated in various European R\&D projects on technology enhanced learning such (i.e., Educomics, IdSpace, WEENET) and serves in the editorial board of international journals. 
Mary Katsamani is a PhD student at Ihe Department of Digital Systems, University of Piraeus in Greece. Her research interests include learning design and design patterns for technology enhanced learning systems. She has participated in European R\&D projects such as Educomics, Idspace, and EPBCII. She is a member of the Computer Supported Learning Engineering Laboratory (CoSyLab) at the University of Piraeus. Meanwhile, she is working as a School Teacher of Informatics in a public secondary school.

\section{Introduction}

Technological opportunities, global, web-based connectivity and the dynamic of the globalised economy confront us with new challenges, and demand new solutions. (European Commission, 2002). The development of creative solutions (creative problem solving, CPS) has even become so pressing that Prahalad and Krishnan (2008) refer to the first decades of the 21 st century as the 'age of innovation'. As a result, the capability to collectively invent new solutions and products has become a core competence of today's knowledge workers (Bhaskar and Martens, 2008; Casalllini et al., 2007; Cerinsek and Dolinsek, 2009; Drucker, 2002).

Analyses of creative projects indicate that it is not only lack of creativity per se that stands in the way of successful co-creative teams and communities. Both the technological nature and the complexity of CPS require contributions of specialists from various domains and communities. These professionals have to collaborate to produce innovative products and services. However, often they are distributed across locations, firms and countries. Hence, their collective performance demands affording electronic 'spaces' that support their distributed work and especially their creative collaboration.

Lack of knowledge and experience of useful creativity techniques can of course also be a barrier to success. Not knowing which method might be helpful to specifically address the problem at hand and lacking an integrated set of tools and knowledge assets on how to apply creative techniques in practice it is unlikely that a team will succeed. Additionally, also the way in which team members collaborate and learn from each other is a potential barrier. Therefore, we argue that creative team performance not only needs support focussed on creativity per se but also integrated supportive actions that cater for all relevant dimensions of the creative collaboration process.

Multiple failures pave the road to success. Often failure proves to be a matter of learning. Sometimes the team's problems are caused by unclear articulation of ideas (Bitter-Rijpkema et al., 2002; Brodbeck and Greitemeyer, 2000; Hakkarainen et al., 2002) at other times they result from miscommunication during collaboration (Bitter-Rijpkema et al., 2002; Schmid, 1996). If initial ideas are not picked up or if they fail to be thoroughly assessed for their value to the team's problem, useful knowledge may easily be discarded already at an early stage (Schmid, 1996). Flaws in knowledge communication hinder not only the process of knowledge building that is meant to realise common ground, they can also frustrate motivation or otherwise block progress (Fischer et al., 2004). Since innovation has become a team activity, coordination of each team member's contribution to the collective goal therefore is decisive for any teams' success (Nemiro, 2004). 
One has become aware that success in CPS is crucial to professional work - whether in face-to-face, well-defined project and team settings or in community-based open formats of innovation. This in turn has stimulated investigations into computer support for CPS (Casallini et al., 2007; Gasco-Hernandez and Torres-Corronas, 2004; Farooq et al., 2005; Huber et al., 2009; Nemiro, 2004; Resnick et al., 2005). The foci of these research initiatives differ. Among them, we find learning aids to enhance creativity, software tools to support the articulation and processing of ideas, and dedicated support systems that help to implement specific creative techniques (Boland and Tenkasi, 1995; Shneiderman, 2006).

In general, in the abundance of creativity research and supportive tools the user has to find out which methods and tools are useful for his purposes. Next, he will have to select the most suitable tools from this fragmented landscape of tools that usually are not interoperable nor open to integration with other tools.

It was the existence of this landscape of abundant but fragmented support tools for collaborative creativity that triggered the work on idSpace. The ambition of the idSpace project was to investigate and design a web-based, integrated support suite able to support innovation teams and communities. The suite should take into account relevant dimensions of the context in which the team acts and in which the applications of creativity techniques are embedded.

\section{An integrated web platform for co-creativity}

The idSpace environment features an integrative toolset that allows a distributed team of innovators to collaboratively create new ideas, contribute to and preserve existing ideas, as well as increase the collective knowledge.

IdSpace takes an idea as its starting point; it is viewed as a standalone, first class semantic entity. Any idea is used for reference purposes, whenever a refinement is made or whenever it becomes part of a new point of view. Referrals (i.e., links) between idea entities and their refinements are used for navigation, exploration, as well as context-aware recommendation purposes. The idSpace project designed and developed a web-based, extensible platform that facilitates the co-construction of novel ideas through distributed collaboration. The platform facilitates the exploration of different viewpoints through the support that its different tools offer.

1 idSpace thus harbours two notions of space

- semantic - a network of ideas, meaning, relationships and their refinements

- technical - a platform which supports collaborative, distributed innovation and creativity.

2 The platform therefore contains

- An integrated toolset, which will help to track and to store semantic relationships among conceptual models (the space as a network of ideas), to be used to describe innovative ideas, product features, stories about the ideas and all other kinds of knowledge towards product creation. 
- Extensible, informal, pluggable pedagogical (knowledge sharing) recommendations aimed at enhancing appropriate application of creativity techniques for innovation. Jointly, these knowledge sharing and development recommendations drive specific uses of the integrated toolset.

- Context-aware support mechanisms that dynamically adapt the idSpace platform to learners' actions, contexts and competences.

It employs techniques for exploring new ideas (e.g., concept mapping and brainstorming) and for refinement of ideas (e.g., morphological analysis). It also supports traceability and reasoning among the ideas presented in the concept maps. This can be achieved because the idSpace environment preserves semantic relationships among the different concepts for further exploration, retrieval, and navigation purposes.

The integrated toolset allows a design team to generate new ideas, contribute to and preserve existing ideas, and to learn about them. IdSpace is designed to employ a large variety of creativity techniques for exploring new ideas, such as mind mapping in story writing, brainstorming, lateral thinking, critiquing (the current prototype features only supports one technique fully, though). The platform preserves semantic relationships among the different viewpoints for exploration, retrieval, and navigation purposes. A sketching tool is part of the platform, which allows one to contribute without fully structuring one's ideas and connect them with existing ideas.

Figure 1 Screenshot of idSpace environment (see online version for colours)

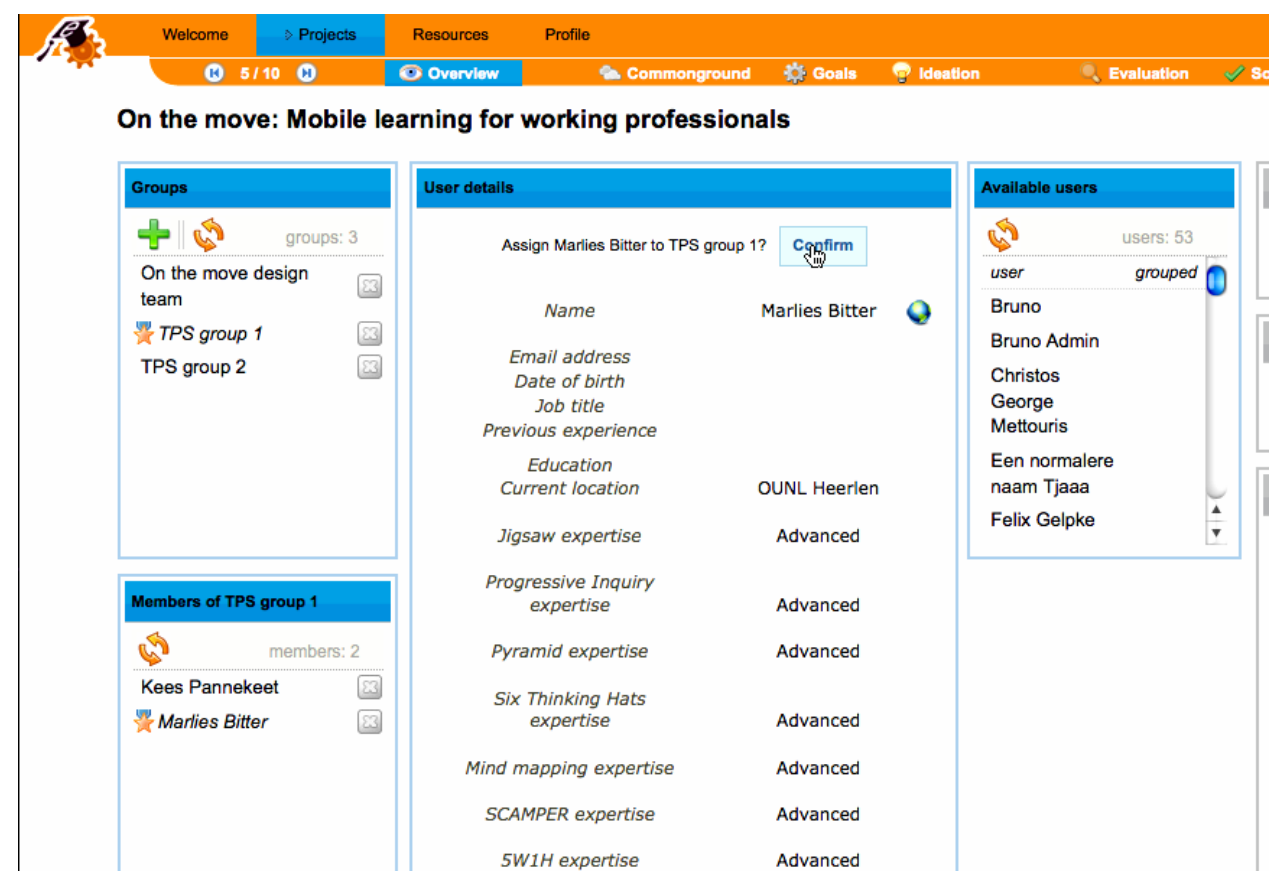

The project also carried out a comprehensive analysis of pedagogical approaches which are useful in the various stages of product innovation. They provide an educational perspective on how to engage people in the generation of new ideas and in the definition of innovative designs and features or the combination thereof. Characteristic of the 
idSpace platform is that it responds to changes of the context, such as tools currently displayed at a user interface, learning state and competence, stage of the innovation process, activity currently performed.

In short, the idSpace environment enables the use of various creativity techniques. After having chosen a creativity technique, the moderator selects the appropriate collaborative learning strategy which will prescribe the flow of the collaborative creativity process which will be explained in the following section. The moderator can also compose groups and subgroups for the various collaborative tasks. Group members are selected based on their profiles and their availability. A screenshot of the idSpace environment is shown in Figure 1.

The idSpace environment is based on the Liferay multi-awarded, open source platform (http://www.liferay.com/) in which the required functionalities have been incorporated as portlets. Liferay uses Java and Web 2.0 technologies. It offers dynamic and intuitive content management, web publishing, collaboration and social networking options.

\section{Pedagogical flow patterns for creative collaboration}

The design of tools that can support collaborative creativity sessions is a complex task. Designers (particularly novice ones) need guidance, advice and support in order to produce effective designs. On the one hand, guidance and advice need to be based on solid research and empirical findings. On the other hand, they should not be too prescriptive, or based on a single model, since they will not help designers to create innovative designs, suited to their particular context, that make the most of new and evolving technology. As pointed out by Hernandez-Leo et al. (2005), design patterns (DPs) provide software developers with information about the flow of learning activities that are expected to occur during a collaborative learning scenario based on a pedagogical strategy which the flow pattern analyses.

Furthermore, Borchers (2001) suggested that DPs have more advantages than style guides, guidelines, and standards "through their structured inclusion of existing examples and insightful explanation not only of the solution, but also of the problem context in which this solution can be used, and the structured way in which patterns are integrated into the hierarchy of the language". This opinion is in line with several other researchers in the domain of interaction design such as Tidwell (2008) and Bayle et al. (1998), who asserted that DPs are very valuable because they are driven from design practice, are based on examples, are presented into multiple levels of abstraction, and are interrelated and thus facilitate piecemeal development.

Figure 2 shows the way in which DPs are used in the idSpace environment. Starting from a more conceptual level which concerns the pedagogical and creativity strategies, more specific designs in the form of flow DPs (collaborative learning flow patterns - CLFP and creativity flow patterns - CreFP) can be created. The term 'flow' is used to portray coordination and sequencing of learning tasks. In order to support the mix and match of the flow DPs, the knowledge-sharing strategies for collaborative creativity (KS4CC) framework has been proposed as will be explained in the next section. KS4CC consist of combinations of CLFPs and CreFPs, based on user selection and customised recommendations (awareness). 
Figure 2 Flow patterns in idSpace

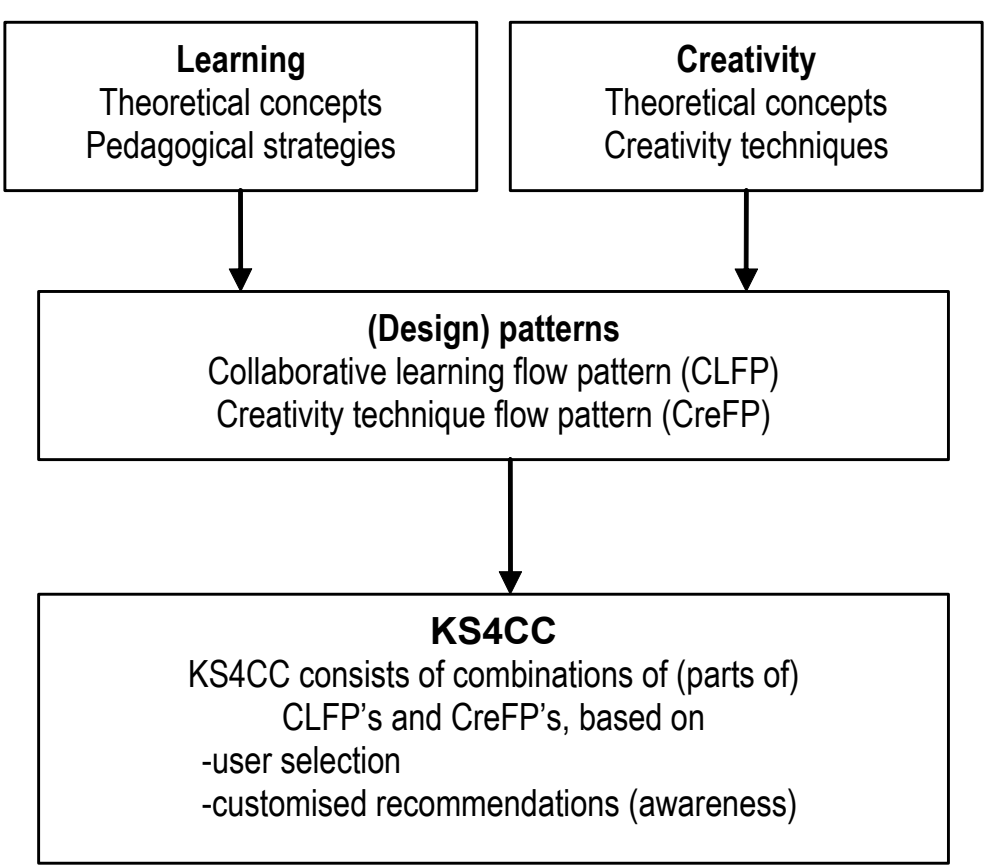

DPs play the role of lingua franca so that the idSpace environment designing team can understand its functional requirements. A similar concept of the way DPs can be used to bridge the gap between instructional designers and software engineers can be found in (Turani and Calvo, 2006).

\section{Knowledge-sharing strategies for collaborative creativity}

\subsection{Collaborative creativity: team creativity as a matter of collaborative learning}

As you have noticed we argue that the process of collaborative invention of new products or services, whether in the context of a (consumer) community or of a well-defined (corporate) team, requires more than availability of computer support for the execution of a specific creativity technique, such as brainstorming, Scamper or the Six Hats method (Bitter-Rijpkema et al., 2009; Georgiakakis et al., 2009).

To optimise creative collaboration and achieve collective creative results team members need to realise effective creative collaboration across all phases of the project and all project dimensions (Boland and Tenkasi, 1995; Fischer et al., 2009; Franke and Shah, 2003). We assume that unlashing the collective creative potential of the team asks for coordinated action, for example by respecting each person's CPS style while at the same time finding concurrent ways for coordinated team progress.

The act of co-creation is very much a matter of learning. First of all learning to select and use new CPS methods. Each creative technique has its specific characteristics. For specific problem types, contexts and team types a specific creativity technique (further 
on abbreviated as CT) is more appropriate than another technique. The idSpace creativity technique selector (Grube and Schmid, 2008) supports guidance to select an appropriate technique (i.e., Six Hats) based on context (i.e., web-based), activity (different perspectives) and operation type (i.e., idea exploration) and team type (single group) (Boden, 2004; Grube and Schmid, 2008).

Support that the creative techniques provide aim at fostering creativity through processes of systematic idea articulation, visualisation, systematic questioning etcetera whereas pedagogical strategies promote necessary collaborative learning. Our idea is that merging learning strategies with support of creative techniques to which we refer as $\mathrm{KS} 4 \mathrm{CC}$ is what is needed.

KS4CCs have a wider scope in addressing the innovation team's needs. They deal with challenges that collaborative creativity pose, like how to stimulate generation of enough and qualitatively good ideas for the problem at hand, prevent ideation failure, enhance comprehension of individual perspectives brought to table and concurrently nurture transformation from initial concepts into matured contributions to a shared solution, as well as managing to keep up a team's motivation till the end.

Problems concerning the aforementioned dimensions, i.e., barriers to the learning flow of a creative collaboration, can seriously hinder the process and limit quality the project outcome. Reason for us to focus on what in our view is missing: application of collaborative learning strategies that foster knowledge sharing and development in settings of collaborative team or community based innovation.

We use KS4CC to label the type of recommendations we think are needed to support the workflow of virtual teams and communities involved in collaborative creativity session, i.e., sessions supported by idSpace. As the name KS4CC suggests the objective of support is a matter of knowledge building and sharing aimed at enhancing the collective creativity of the team.

Figure 3 Knowledge-sharing strategies for collaborative creativity (see online version for colours)

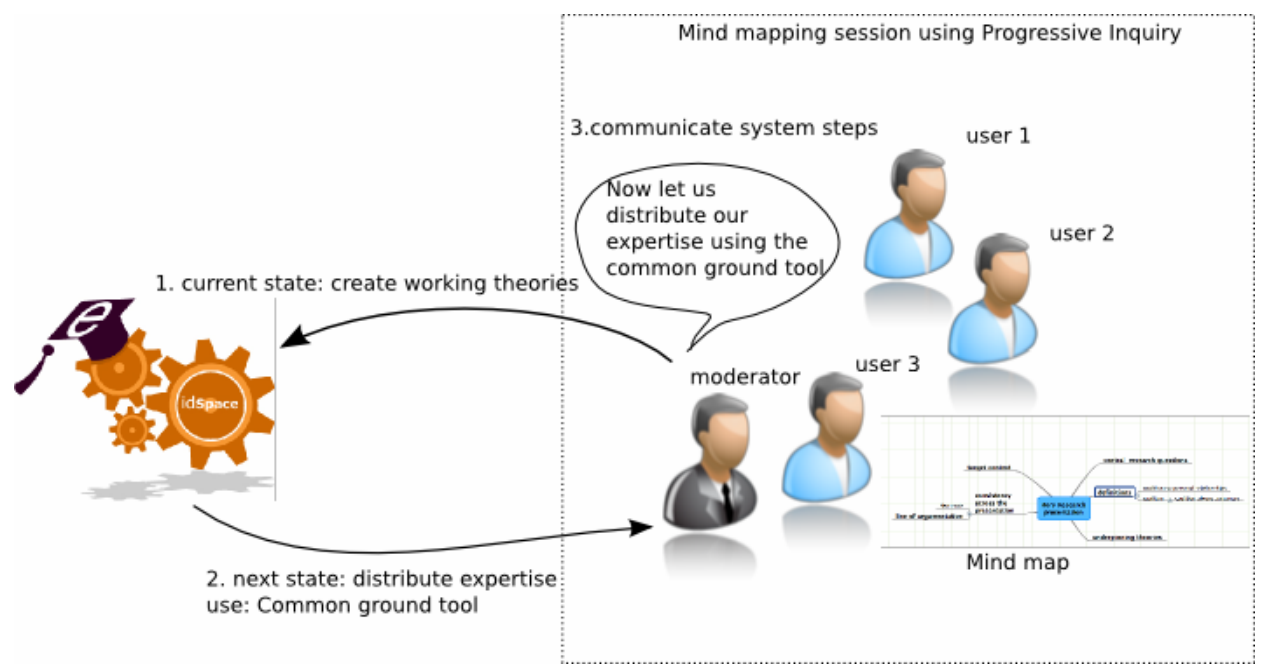

To realise that ambition, we have to search for available heuristics, and develop patterns that address the key dimensions of the co-creative endeavour. 
Figure 4 KS4CC for idSpace

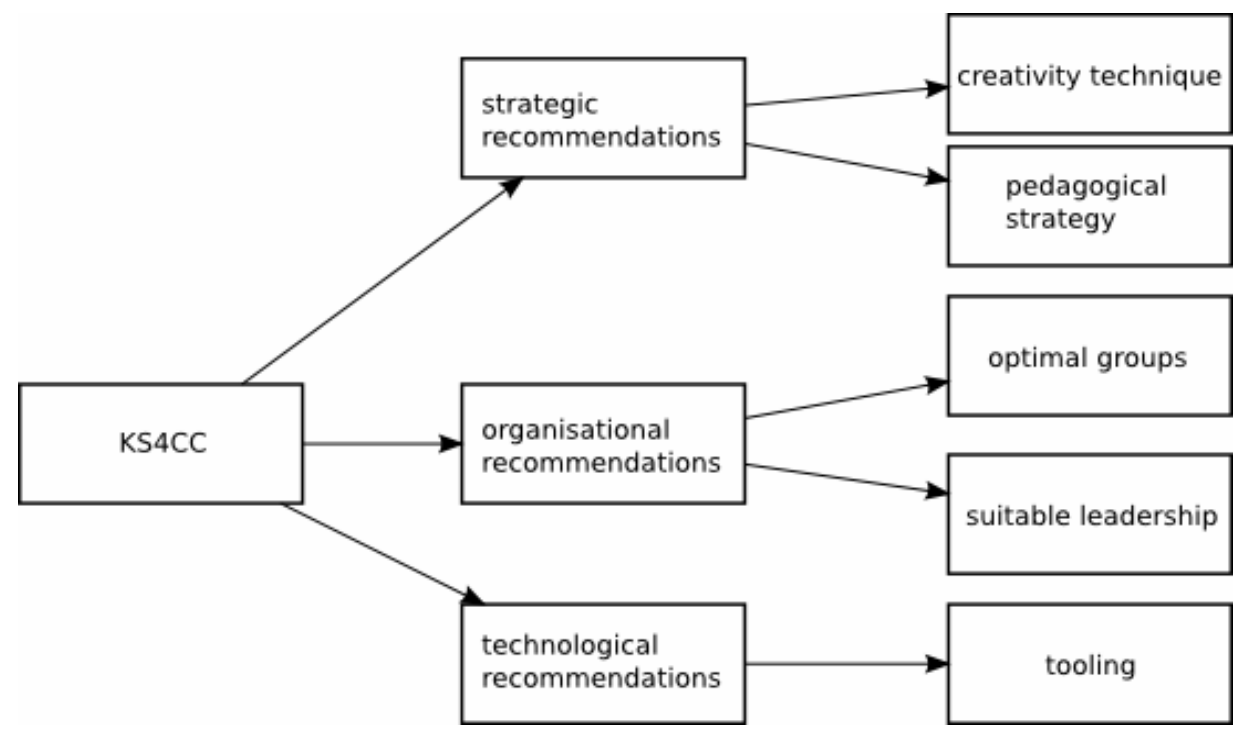

We divide the recommendations into three categories.

1 Strategic or higher order recommendations, recommendations that help team members to choose a creativity technique optimal to their case. Depending on the complexity strategies recommendations might consist of a whole set of interdependent strategies and constituent activities.

2 Organisational recommendations, recommendations that care for formation of optimal groups, give suggestions for suitable leadership, etc.

3 Technological recommendations, recommendations that suggest how to use and integrate specific (technological/computer) tools, and how to implement creativity techniques, computer supported teamwork, etc.

\subsection{Multiple explorations: guided by creativity techniques and learning heuristics}

Based on the observations of the awareness mechanisms, the idSpace flow patterns steer the composition of a set of KS4CC recommendations. As the case may be, patterns aim at enhancing constructive learning processes, at collaborative creative actions (based on CreFP) and at reflections at that stage of the invention process.

Concurrently advice is given on optimal organisation of collaboration (based on a CLFP) and taking advantage of the available computer tools.

KS4CC generate customised sets of suitable recommendations that match the situation of the team. Customisation relies on user input (via the session moderator) and indications from the awareness monitoring mechanism. In this way, integrated strategic support is provided including the creativity technique per se.

KS4CC gives two types of input: 
1 user-directed support

2 workflow-oriented support.

User-directed support is given when a user interacts with the idSpace platform. A user of the platform may be either a moderator or a participant of a (collaborative) creativity session. When a user would like to know about a specific pedagogical strategy, idSpace adopts the specification that represents that strategy. Subsequently, idSpace extracts a definition and shows it to the user, if a user is already familiar with the technique in question, which the awareness module then would indicate, the presentation will have a more condensed format than it otherwise would have had. A definition for first time users of the technique might look as follows (paraphrased for idSpace use, based on Hakkarainen et al., 2002):

\begin{abstract}
"Progressive inquiry relies on an idea of facilitating the same kind of good and productive practices of working with knowledge that characterise scientific research communities in education. By imitating the practices of scientific research communities, team members are encouraged to engage in an extended processes of question, exploration and explanation-driven inquiry. An important aspect of the strategy of progressive inquiry is to guide the investigation journey by working from systematic questioning that originates in articulated working theories. In practice, this means that users make their assumptions and conceptions public and work together to discover shared ideas explanations and opportunities for new use: combining and transforming existing components. Search for new information and re-use of other ideas, i.e. ideas from earlier or other sessions is essential."
\end{abstract}

As you may notice, the above definition lacks a practical guide on how to operationalise the progressive inquiry into a pedagogical strategy. By operationalisation, we mean actions that are necessary as part of the pedagogical strategy's goal to develop new knowledge. The progressive inquiry technique for instance consists of 14 (recurring) actions. One of these actions is called 'create working theories' and is explained by the following text:

"Write down your own working theories on how to solve the problem. Explore and combine steps from other problem solving meetings."

In an electronic environment, these steps have to be translated to functions within the idSpace platform. Therefore, we have decided to develop workflow-oriented support. This so-called workflow-oriented support provides the moderator of a creative session with a number of actions that have to be taken to foster collaborative learning, as part of a pedagogical strategy.

We defined four types of elements within the (XML) specifications of the pedagogical strategy progressive inquiry:

1 states

2 steps

3 processes.

States are actions that have to be taken when using a pedagogical strategy. Below we show how such a state specification for the aforementioned action 'create working theories': 
$<$ state $>$

$<$ state_id $>$ create_working_theories $</$ state_id $>$

$<$ description $>$ Think about /Write down your own working theories how to solve the problem. Explore and combine steps from other problem solving meetings. $<$ description $>$

$<$ process_id $>10<$ process_id $>$

$</$ state $>$

The state specification includes a unique identifier state_id, which is important for linking states to one another by means of a transition called a 'step'. Such a step consists of an identifier and two subsequent states (fromState and toState), which is shown below:

$<$ step $>$

$<$ step_id $>4</$ step_id $>$

$<$ fromState $>$ create_working_theories $<$ /fromState $>$

$<$ toState $>$ distribute_expertise $</$ toState $>$

$</$ step $>$

When we combine several steps, we have a pattern. A pattern is a step-by-step workflow that guides you through a pedagogical strategy for collaborative learning. Such a pattern looks as follows:

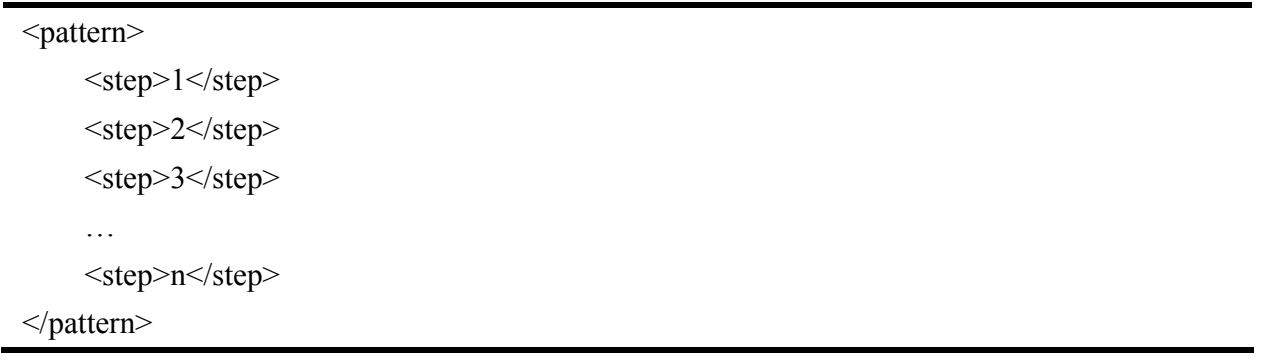

Figure 5 Overview of a KS4CC workflow specification

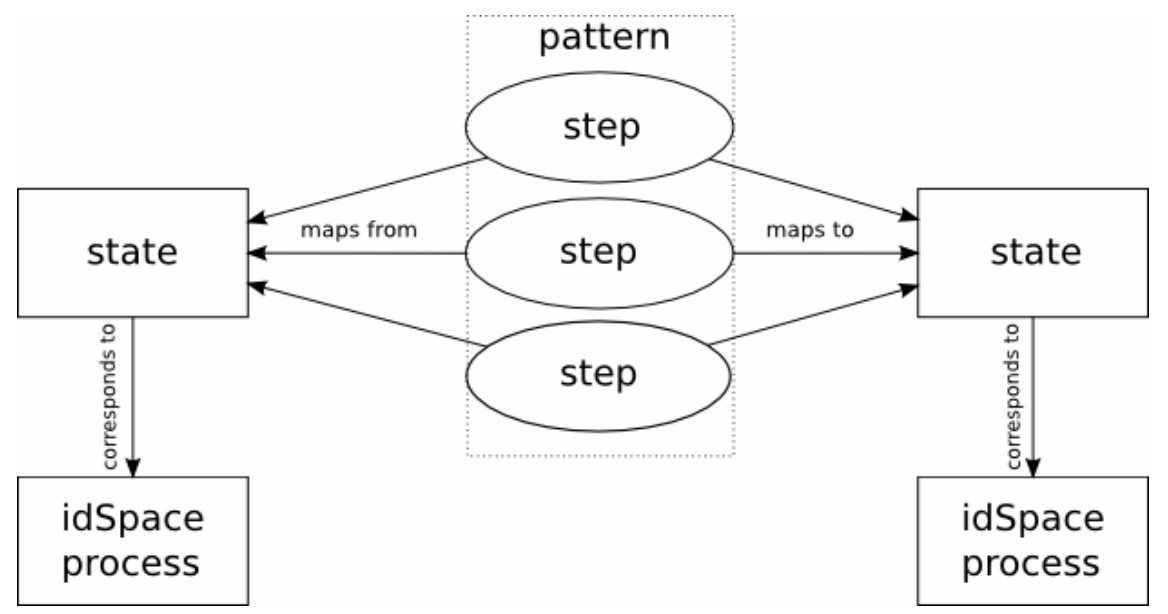


Now, all we have to do is translate this XML specification to idSpace functions. In our XML specifications, referred to as processes. For every function in the idSpace platform, we define a process specification, which includes a unique identifier for links from states to processes. In the XML specification for states this is denoted by for instance $<$ process $i d>10</$ process $i d>$, which links the state to process number 10 . Briefly summarised, we have system functions that are linked to states. These states are linked to one another by steps, and a sequence of step makes a pedagogical pattern. To simplify understanding, we depicted the structure in Figure 5.

\section{Conclusions and future work}

Knowledge professionals are expected to find new - often technologically advanced solutions to rather complex problems. This requires professionals from different domains and communities to work together in distributed settings. However, it proves to be quite difficult for such teams and communities to successfully realise the envisaged inventive results.

Analyses of existing practices point to multiple problems that prevent smooth development of creative collaboration. Inadequate, fragmented tooling, lack of knowledge and experience with creativity techniques, problems with learning, unawareness of existing ideas and problems when choosing optimal collaboration and organisational strategies for a team's specific context block the creative potential of the group.

Figure $6 \mathrm{KS} 4 \mathrm{CC}$ recommendations (see online version for colours)

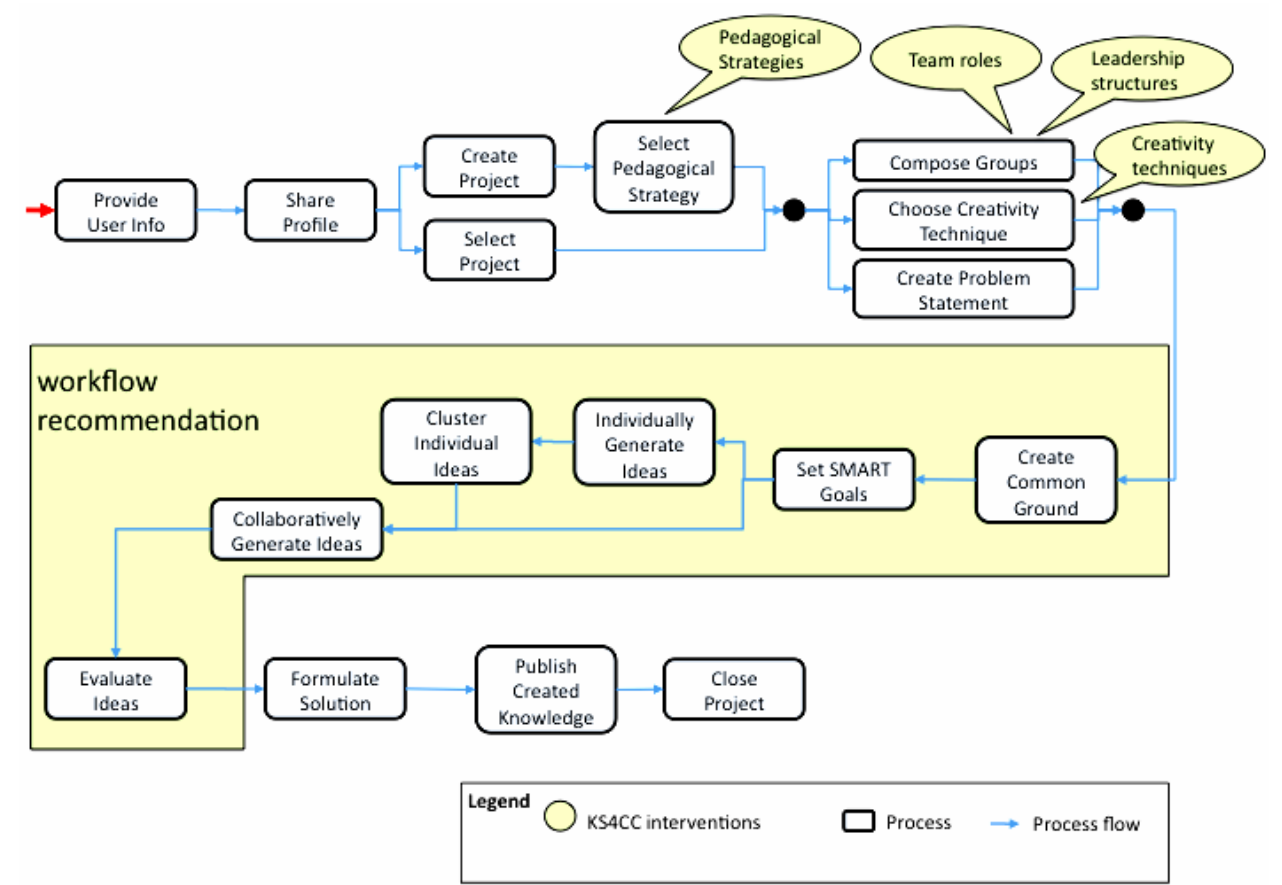


Hence, the ambition of idSpace to present a platform that offers integrated tooling for co-creativity. The platform takes into account concurrent support across all key dimensions with the aim to optimally enhance creative collaboration of teams and communities. In this paper, we described how we provide support based on patterns, i.e., heuristics of successful KS4CC fitting the team's needs. Figure 6 shows junctures within the workflow where KS4CC advice is given. Elaborating the number of strategies and developing new patterns is one way to provide creativity support However, we are convinced dedicated advice is possible at yet other areas in the workflow.

The idSpace environment was originally developed with creative collaboration in mind by teams working on new product design. In our view though, the conceptual framework as well as the platform are suitable for groups working in different contexts, domains and work settings. IdSpace is able to provide support for a well-defined project team that applies CPS methods to incrementally improve an existing product. But it can just as well enhance creativity of user groupings in communities that sharing a passion for sports or create new equipment or are led by consumers in their exploration of new opportunities (consumer-led innovation, cf. von Hippel, 2001; Huber et al., 2009; Sawhney and Prandelli, 2000). Knowledge about the actual interactions between people in ideation sessions can help to improve existing KS4CC recommendations. When people support each other's ideas by either consciously supporting each other, or by unconsciously elaborating on someone's idea, they form sub groups, or coalitions (Sie et al., 2009). This is an issue that needs further investigation.

To conclude, idSpace tried to respond to the need for support for ideation and solution finding. We defined new ways to approach collaborative creativity and support group members. It can be used by web-based teams and communities, whether engaged in work-related activities or addressing leisure-related problems. The effectiveness of the integrative platform is currently tested by exposing it to innovation experts and innovators; this will provide input to further develop the platform, also for other users groups.

\section{Acknowledgements}

We would like to thank our idSpace peers for our collective work and discussions that inspired this paper. The present work was carried out as part of the idSpace project on tooling and training for collaborative product innovation (http://idspace-project.org). This project is partially supported by the European community under the information and communication technologies (ICT) theme of the 7th Framework Programme for R\&D (FP7-IST-2007-1-41, Project Number 216799). This document does not represent the opinion of the European community, and the European community is not responsible for any use that might be made of its content.

\section{References}

Bayle, E., Bellamy, R., Casaday, G., Erickson, T. et al. (1998) 'Putting it all together: towards a pattern language for interaction design', SIGCHI Bulletin, Vol. 30, No. 1, pp.17-23.

Bhaskar, P. and Martens, R. (2008) 'Increasing technological innovation competence through intraorganizational communication networks', Competence Building and Leveraging in Interorganizational Relations, pp.141-165, Amsterdam, Elsevier. 
Bitter-Rijpkema, M., Martens, R. and Jochems, W. (2002) 'Supporting knowledge elicitation for learning in virtual teams', Educational Technology \& Society, Vol. 5, No. 2, pp.113-118, available at http://www.ifets.info/journals/5_2/rijpkema.pdf (accessed on 6 July 2011).

Bitter-Rijpkema, M., Pannekeet, K. and Rutjens, M. (2009) 'Recommendations for e-learning in new product development teams', in Hambach, S., Martens, A., Tavangarian, D. and Urban, B. (Eds.): Proceedings of the 2nd International eLBa Science Conference, 17-19 June 2009, Fraunhofer IRB Verlag, Stuttgart, Rostock, Germany, pp.135-145, available at http://www.hdl.handle.net/1820/1976.

Boden, M.A. (2004) The Creative Mind: Myths and Mechanisms, 2nd ed., Routledge, London.

Boland, R.J. and Tenkasi, R.V. (1995) 'Perspective making and perspective taking in communities of knowing', Organization Science, Vol. 6, No. 4, pp.350-372.

Borchers, J.O. (2001) 'A pattern approach to interaction design', AI Soc., Vol. 15, No. 4, pp.359-376.

Brodbeck, F.C. and Greitemeyer, T. (2000) 'A dynamic model of group performance: considering the group members' capacity to learn', Group Processes and Intergroup Relations, Vol. 3, No. 2, pp.159-182, available at http://gpi.sagepub.com/content/3/2/159 (accessed on 6 July 2011).

Casalllini, M.C., Janowski, T. and Estevez, E. (2007) A Process Model for Collaborative Problem Solving in Virtual Communities of Practice, April 2007, Technical report, International Institute for Software Technology, United Nations University.

Cerinsek, G. and Dolinsek, S. (2009) 'Identifying employees' innovation competency in organisations', Int. J. of Innovation and Learning 2009, Vol. 6, No. 2, pp.164-177.

Drucker, P.F. (2002) 'The discipline of innovation', Harvard Business Review, August, pp.95-102.

European Commission (2002) Towards a Knowledge-based Europe: The European Union and the Information Society, European Communities, Brussel/Bruxelles.

Farooq, U., Carroll, J.M. and Gannoe, C.H. (2005) 'Supporting creativity in distributed scientific communities', Proc. of Group'05, ACM Press, New York, NY, pp.217-226.

Fischer, G., Jennings, P., Maher, M., Resnick, M. and Shneiderman, B. (2009) 'Creativity challenges and opportunities in social computing', Proceedings of the 27th International Conference Extended Abstracts on Human Factors in Computing Systems, 4-9 April 2009, Boston, MA, USA, pp.3283-3286, CHI EA '09, ACM, New York, NY.

Fischer, G., Scharff, E. and Ye, Y. (2004) 'Fostering social creativity by increasing social capital', in Huysman, M. and Wulf, V. (Eds.): Social Capital and Information Technology, pp.355-399, MIT Press, Cambridge, MA.

Franke, N. and Shah, S.K. (2003) 'How communities support innovative activities: an exploration of assistance and sharing among end-users', Research Policy, Vol. 32, No. 1, pp.157-178.

Gasco-Hernandez, M. and Torres-Corronas, T. (2004) 'Virtual teams and their search for creativity', Virtual and Collaborative Teams, Idea Group, Hershey, PA.

Georgiakakis, P., Retalis, S., Bitter-Rijpkema, M., Pannekeet, K., Rutjens, M. and Sloep, P.B. (2009) 'Design patterns as guidance for designers of groupware used by team for the development of innovative products', E-Learning Patterns Workshop, 4-6 May, Knowledge Media Research Centre, Tübingen, Germany, available at http://hdl.handle.net/1820/2167.

Grube, P. and Schmid, K. (2008) Creativity Technique Selector, available at http://repository.sse. uni-hildesheim.de/CreativityTechniqueSelector/ (accessed on 6 July 2011).

Hakkarainen, K., Lipponen, L. and Jarvala, S. (2002) 'Epistemology of inquiry and computer-supported collaborative learning', in Koschmann, T., Miyake, N. and Hall, R. (Eds.): CSCL2: Carrying Forward the Conversation, Erlbaum, Mahwah, NJ.

Hernandez-Leo, D., Asensio-Perez, J.I. and Dimitriadis, Y. (2005) 'Computational representation of collaborative learning flow patterns using IMS learning design', Educational Technology \& Society, Vol. 8, No. 4, pp.75-89. 
Huber, M.J., Bretschneider, U., Leimeister, J.M. and Krcmar, H. (2009) 'Making innovation happen: tool-support for software related communities for innovations', in Pipek, V. and Rohde, M. (Eds.): International Reports on Socio-Informatics - Open Design Spaces Supporting User Innovation, Proceedings of the International Workshop on Open Design Spaces (ODS'09), IISI - International Institute for Socio-Informatics, Bonn, S.22-32.

Nemiro, J. (2004) Creativity in Virtual Teams: Key Components for Success, John Wiley \& Sons, Inc., San Francisco.

Prahalad, C.K. and Krishnan, M.S. (2008) The Age of Innovation, Driving Co-created Value through Global Networks, McGraw-Hill, New York.

Resnick, M., Myers, B., Nakakoij, K., Shneiderman, B., Pausch, R., Selker, T. and Eisenberg, M. (2005) 'Design principles for tools to support creative thinking', Creativity Support Tools: Report from a US National Science Foundation Sponsored Workshop.

Sawhney, M. and Prandelli, E. (2000) 'Communities of creation: managing distributed innovation in turbulent markets', California Management Review, Vol. 42, No. 4, pp.24-55.

Schmid, K. (1996) 'Making AI systems more creative: the IPC-model', Knowl.-Based Syst., Vol. 9, No. 6, pp.385-397.

Shneiderman, B. (2006) 'Creativity support tools: report from a US national science foundation sponsored workshop', International Journal of Human-Computer Studies, Vol. 20, No. 2, pp.61-77.

Sie, R.L.L., Bitter-Rijpkema, M. and Sloep, P.B. (2009) 'Knowledge sharing strategies for collaborative creativity', in Retalis, S. and Sloep, P.B. (Eds.): Proceedings of idSpace Workshop on Methods \& Tools for Computer Supported Collaborative Creativity Process: Linking Creativity \& Informal Learning, EC-TEL 2009, 30 September 2009, Nice, France, Published on CEURWS, available at http://sunsite.informatik.rwth-aachen.de/Publications/ CEUR-WS/Vol-536/paper5.pdf (accessed on 6 July 2011).

Tidwell, J. (2008) Common Ground: A Pattern Language for Human-Computer Interface Design, MIT, available at http://www.mit.edu/ jtidwell/interaction_patterns.html (accessed on 20 January 2010).

Turani, A. and Calvo, R.A. (2006) 'Beehive: a software application for synchronous collaborative learning', Campus Wide Information Systems, Vol. 23, No. 3, pp.196-209.

von Hippel, E. (2001) 'Innovation by user communities: learning from open-source software', MIT Sloan Manag. Rev., Vol. 42, No. 4, pp.82-86. 